

\section{DISCLAIMER}

This report was prepared as an account of work sponsored by an agency of the United States Government. Neither the United States Government nor any agency Thereof, nor any of their employees, makes any warranty, express or implied, or assumes any legal liability or responsibility for the accuracy, completeness, or usefulness of any information, apparatus, product, or process disclosed, or represents that its use would not infringe privately owned rights. Reference herein to any specific commercial product, process, or service by trade name, trademark, manufacturer, or otherwise does not necessarily constitute or imply its endorsement, recommendation, or favoring by the United States Government or any agency thereof. The views and opinions of authors expressed herein do not necessarily state or reflect those of the United States Government or any agency thereof. 


\section{DISCLAIMER}

Portions of this document may be illegible in electronic image products. Images are produced from the best available original document. 
"This report was prepared as an account of work sponsored by the United States Government. Neither the United States nor the United States Energy Research \& Development Administration, nor any of their employees, nor any of their contractors, subcontractors, or their employees, makes any warranty, express or implied, or assumes any legal liability or responsibility for the accuracy, completeness or usefulness of any information, apparatus, product or process disclosed, or represents that its use would not infringe privately-owned rights."

Printed in the United States of America Available from

National Technical Information Service U.S. Department of Commerce 5285 Port Royal Road Springfield, Virginia 22151

Printed Copy $\$$ _ * Microfiche $\$ 2.25$

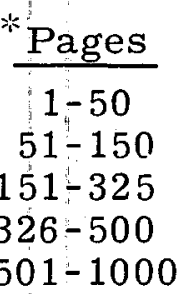

NTIS Selling Price

$\$ 4.00$

$\$ 5.45$

$\$ 7.60$

$\$ 10.60$

$\$ 13.60$ 


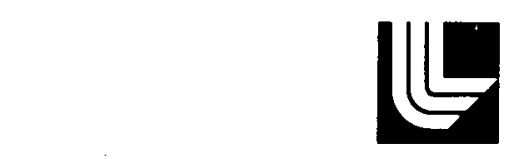

LAWRENCE LVERMORE LABORATORY

University of Caffornia / Livermore, Califomia, 94550

UCRL-52000-75-5

\title{
LAWRENCE LIVERMORE LABORATORY ENERGY AND TECHNOLOGY REVIEW
}

\author{
Scientific Editors: Ronald B. Carr \\ Philip E. Coyle \\ General Editors: Judith M. Barnett \\ Robert C. Berlo \\ Charles S. McCaleb \\ Judyth K. Prono
}

May 1975

\begin{abstract}
This report was prepared as an account of work This report was prepared as an account of work
sponsored by the United States Government. Neither the United States nor the United States Energy Research and Development Administration, nor any of their employees, nor any of their contractors, subcontractors, or their employees, makes any warranty, express or implied, or assumes any legal liability or responsibility for the accuracy, completeness or usefulness of any information, apparatus, product or process disclosed, or represents that its use would not infringe privately owned rights.
\end{abstract}




\section{Briefs}

The short items on this page announce recent developments of importance. Some of these items may be amplified in future issues. None of this material is reported elsewhere in this issue; summaries of this month's articles appear on the opposite page.

\section{LASER PROGRAM ACHIEVES RECORD NEUTRON YIELDS}

On May 15, LLL produced a record number of neutrons in a laser-fusion implosion: $1.1 \pm 0.2 \times 10^{7}$. The microscopic targets for this experimental series were of the exploding-pusher variety first developed at Livermore in 1970. Exploding-pusher targets were selected for our initial experiments because they are relatively insensitive to possible hydrodynamic and plasma instabilities.

We achieved the higher neutron yield using both arms of the Janus laser system impinging on a target whose specific design has not yet been released. The two diametrically opposed laser beams produced 75-ps pulses of 18.1 and $18.7 \mathrm{~J}$, which were focused by $\mathrm{f} / 1.1$ lenses at the median plane of the capsule. Prompt neutron diagnostics recorded the production of the 11 million 14-MeV neutrons.

Target yields for this and earlier experiments have been predicted by our implosion codes. This suggests that observed neutrons are from D-T compression and genuine thermonuclear burn rather than from reactions of accelerated, non-Maxwellian fuel ions. This distinction is important because it reflects the ability of our codes to chart the path to laser-fusion breakeven. Having attained $10^{7}$ neutrons, we may now be able to determine the temperature of the reacting D-T ions by measuring the reaction-produced alpha spectral broadening. Within a month, the Cyclops laser will begin operation, first with a 40-J, 100-ps beam and later with an 80-J, 100-ps beam. Irradiations at Cyclops may produce $10^{8}$ neutrons, permitting a direct neutron spectral measurement for determining the D-T burn temperature.

\section{DYNAMITE TAGGING STUDY COMPLETED}

Under an interagency agreement with the Law Enforcement Assistance Administration of the Department of Justice, we have evaluated the technical and economic feasibility of three schemes for tagging (coding) nitroglycerine-based dynamite, a common explosive in criminal bombings. To be useful, the tagging material must not only survive detonation but also be readily retrieved and analyzed. For each scheme, we studied (1) taggant compatibility (chemical reactions with ingredients) and sensitivity (effect on detonation), (2) behavior of tagged dynamite in controlled and "typical" environments, (3) taggant survivability and retrievability, (4) procedures for analyzing retrieved tags, and (5) the economic and manufacturing impact of a tagging scheme.

Our study showed that tagging most commercial cartridge explosives is both technically and economically feasible. We found that recoverable taggants having no adverse effect on the dynamite could be introduced in the production stream of explosive plants at a total cost of less than $0.5 \$$ per kilogram of explosive. These results were forwarded to the U.S. Treasury Department's Bureau of Alcohol, Tobacco and Firearms, where a national explosivetagging program is being formulated.

\section{HYDROGEOCHEMICAL SURVEY TO LOCATE URANIUM SOURCES}

The Laboratory has begun a survey to locate potential areas for uranium mining. Our work is part of ERDA's National Uranium Resources Evaluation (NURE), the first systematic survey of present and potential domestic uranium supply. Projected increases in nuclear power plants impose demands for increased uranium supplies; to meet these demands, more uranium sources that can be mined economically must be located. NURE involves both aerial and surface surveys. We will make surface surveys in California, Oregon, Washington, Nevada, Arizona, Idaho, and Utah. ERDA facilities at Los Alamos, Oak Ridge, and Savannah River will undertake surface surveys in their geographic regions.

Our search will be based on an investigation of uranium's hydrogeochemical characteristics - the presence and transport of uranium and associated elements in streams, sediments, and ground waters. The first step will be pilot projects to characterize each geologic province in our region, so we can identify areas that are geologically most likely to contain uranium.

We will then take hydrogeochemical samples for chemical and physical analysis. The resulting data will be computer-analyzed using pattern recognition, an iterative technique that can sift and classify large amounts of data. These analyses will help us map areas of anomalous uranium content that may be fruitful for exploration.

Follow-up studies will be needed to estimate the commercial potential of these areas. ERDA will undertake some explorations; it is hoped that private industry will also participate. The final product of the NURE program will be a report, produced early in 1980 , combining all survey and exploration results into a comprehensive description of present and potential uranium-mining areas in the U.S. 


\section{Contents}

\section{ADVANCED ENERGY SYSTEMS}

Aerial Prospecting for Geothermal Resources . . . . . . . . . . . . . . . . . . . . . . . . . . 1

We are developing a promising new aerial-reconnaissance method for identifying and evaluating potentially valuable geothermal resource areas. The method is based on using signal ratios of multiple infrared bands to attain the needed temperature sensitivity and a digital surface-climate model to remove from the data the variations due to nongeothermal effects. Preliminary tests have successfully demonstrated both the signal-ratio method and the surface-climate model.

\section{ENVIRONMENT AND SAFETY}

Seismic Response Analysis of a Nuclear Fuel Fabrication Plant . . . . . . . . . . . . . . 5

We evaluated the structural integrity and possible failure modes of nuclear fuel fabrication plants subjected to seismic intensities up to $9.8 \mathrm{~m} / \mathrm{s}^{2}(1.0 \mathrm{~g})$ peak ground acceleration. After determining the ground-motion input, we performed elastic and inelastic analyses on a calculational model of the main structure. We conclude that there is no structural damage below $3.9 \mathrm{~m} / \mathrm{s}^{2}$, moderate to severe structural damage at 3.9 to $4.9 \mathrm{~m} / \mathrm{s}^{2}$, and complete building collapse above $4.9 \mathrm{~m} / \mathrm{s}^{2}$. Examination of representative equipment shows that building collapse will occur before equipment failure.

Radon Sealants for Uranium Mines . . . . . . . . . . . . . . . . . . . . . . 9

The radioactivity in uranium mines poses a serious health hazard for miners. To reduce this radioactivity, the U.S. Bureau of Mines is now evaluating the feasibility of coating the mine walls with protective sealants. We recently completed a study for the Bureau in which we developed preliminary criteria for evaluating potential sealants and examined specific sealants for toxicity.

\section{SCIENCE AND TECHNOLOGY}

Computer-Controlled Multiple-Actuator Shaker Offers Unique Test Capabilities . . . . . . . . . . . . 12

Our dynamic multiple-actuator shaker facility at Site 300, developed for weapons testing, is now also being used for such studies as shock and vibration tests of rocket motors, seismic qualification of a turbine-generator set, and performance analysis of the rock bolts used in mine-tunnel construction. Main features include a capability for testing large, rigid loads over a wide frequency range; real-time data acquisition and display; safe testing of hazardous materials; and a computerized control system that allows the shaker to be easily adapted to nonstandard tests. We envision the facility being used for a wide variety of projects.

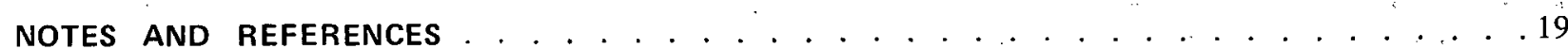



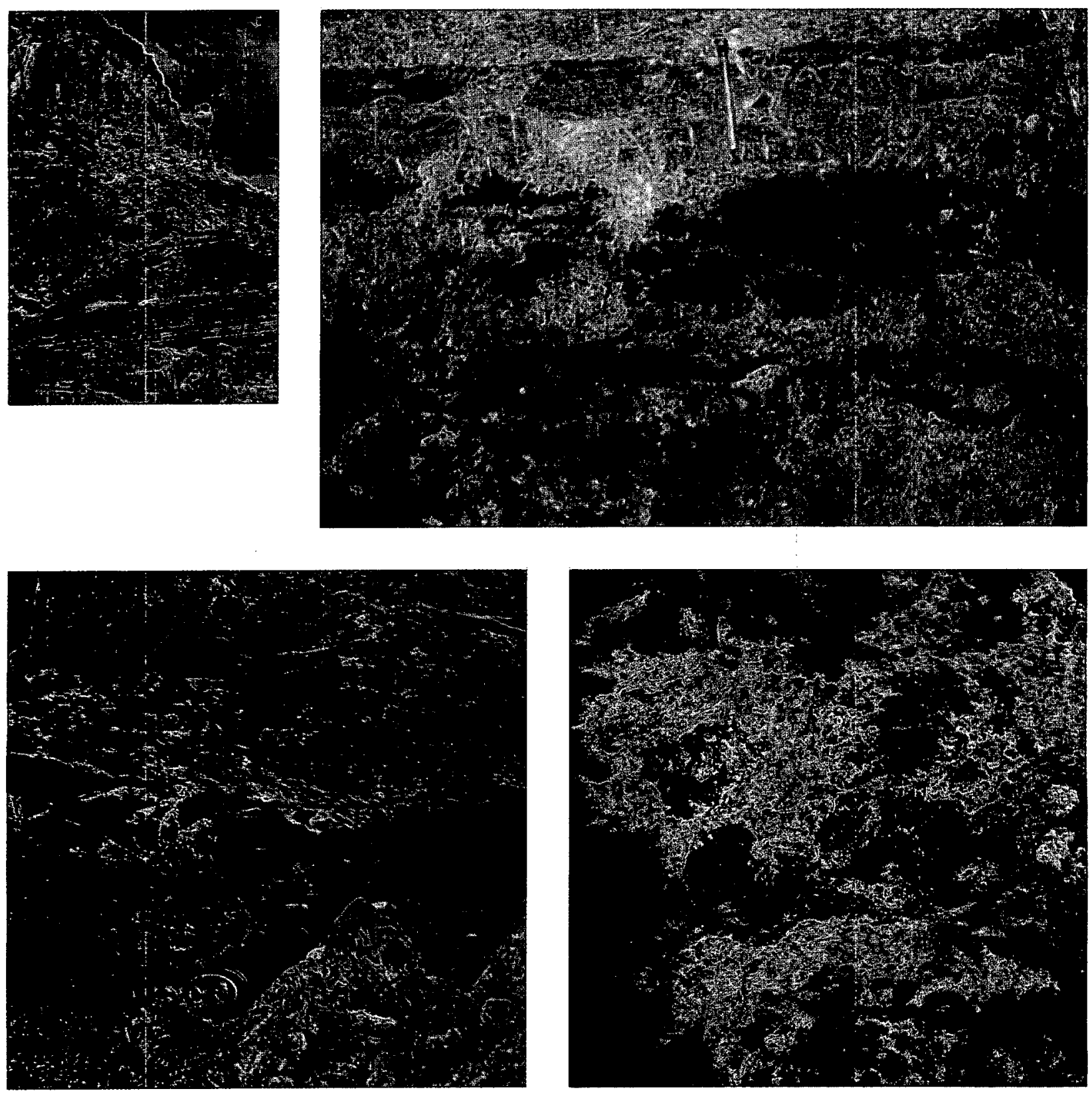

The ores in uranium mines (upper left) continuously generate radon gas, posing a severe health hazard for miners. The primary or common ore, uraninite, is black (see upper right). Common secondary minerals include yellow calciocarnotite or tyuyamunite (lower left) and bright yellow uranopilite, dark yellow zippeite, and green johannite (all lower right). The U.S. Bureau of Mines is now evaluating the feasibility of coating the mine walls with a sealant to impede the circulation of radon gas. We have developed preliminary criteria for evaluating potential sealants and examined specific sealants for toxicity (see article beginning on p.9). 


\section{ADVANCED ENERGY SYSTEMS}

\section{AERIAL PROSPECTING FOR GEOTHERMAL RESOURCES}

We are developing a promising new aerialreconnaissance method for identifying and evaluating potentially valuable geothermal resource areas. The small surface-temperature anomalies often associated with geothermal-resource land usually cannot be detected by existing aerial infrared methods. What is needed is a tenfold improvement in present instrumental temperature sensitivity and a methodology for factoring out the small temperature variations caused by nongeothermal effects.

We have designed a geothermal energy multiband (GEM) system that uses signal ratios to attain the needed temperature sensitivity. These ratios vary as a high power of the absolute surface temperature and are relatively insensitive to the nature of the surface cover. We are developing a methodology that will specify the environmental conditions for effective surveys and correct for nongeothermal effects. Preliminary tests of this methodology have successfully demonstrated both the ratio detection method and the climatological model for simulating the surface temperatures expected in the absence of geothermal effects. The differences between this simulation and actual mean temperatures measured over a nongeothermal area were only $0.01 \mathrm{~K}$ for dry vegetation and $0.15 \mathrm{~K}$ for green vegetation.

Geothermal energy is one of the more promising new energy sources now being considered for the future. The U.S. goal is to generate $2 \mathrm{GW}$ by 1985 and $200 \mathrm{GW}$ by 2020 from geothermal resources. To achieve these goals it will be necessary to develop more effective and economical exploration methods.

The potentially valuable geothermal resource base of the country occupies some $390000 \mathrm{~km}^{2}$ (96 million acres) in the western third of conterminous U.S. These lands must be evaluated; the exact location, size, and potential of the geothermal fields are poorly known. To interest utilities in developing a new geothermal field, at least two years and $\$ 3$ to $\$ 6$ million must be spent proving that the field has a potential of 200 to $400 \mathrm{MW}$. At present this requires using detailed thermal-gradient surveys to

Contact Nancy Kerr Del Grande (Ext. 7625) for further information on this article. pinpoint some 10 to 12 sites for deep exploratory drilling. However, it would be prohibitively slow and expensive to survey the entire $390000 \mathrm{~km}^{2}$ this way. We have devised an aerial infrared survey technique that would make this large-scale evaluation of geothermal resources practical. Once developed, the method should be able to provide detailed aerial thermal surveys at a small fraction of the cost (in both time and money) of existing methods.

Under good conditions, current aerial infrared methods can identify regions on the earth's surface that are as little as 0.5 to $5 \mathrm{~K}$ warmer than the ambient temperature. A few such surveys (in Italy and New Zealand) have successfully located new areas with hydrothermal activity. However, for aerial surveys to be most useful, they should be able to detect surface-temperature anomalies as small as 0.05 to $0.5 \mathrm{~K}$ extending over an area of a few tens to a few hundreds of square kilometres. Detecting such areas requires a tenfold improvement in existing temperature sensitivity and a methodology for removing from the data the temperature effects not related to geothermal activity - effects due to meteorology, hydrology, topography, and terrain conditions. Recent work, mostly at LLL, has shown that it may be possible to achieve both objectives.

Existing aerial infrared scanning systems measure radiation emitted by the earth in one or at most two infrared bands near the peak of the spectrum radiated by the terrain. These systems are affected by the differences in the emissivity of different natural terrains. Temperature rises less than $2 \mathrm{~K}$ are usually obscured by these emissivity variations.

We have conceived a geothermal energy multiband (GEM) system based on the radiation emitted in seldom-used atmospheric pass bands at 2.2, 3.5, 3.9, 4.8 , and $13.2 \mu \mathrm{m}$. By using ratios of measurements made in these bands, we can realize several major advantages. First, surface emissivity effects for natural terrains are small and can be eliminated using analytical techniques. Second, the ratios vary as a high power of the absolute surface temperature, with the result that smaller temperature differences can be detected. We have found that for typical predawn temperatures, the radiant emittance (power per unit area) of a surface varies as the $50 / \lambda$ power of the absolute temperature, 


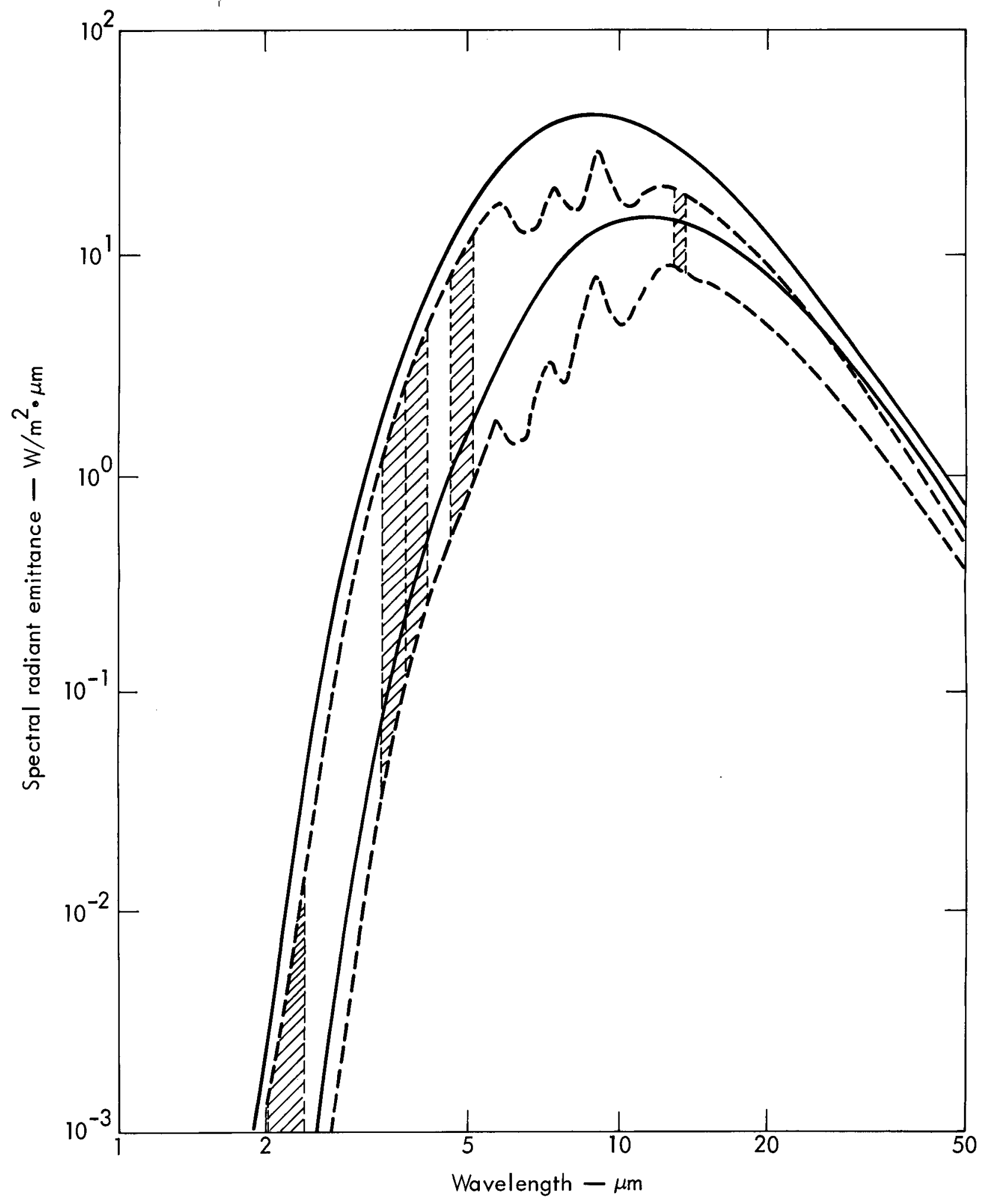

Fig. 1. Emission of the earth's surface at infrared wavelengths. The solid curves represent ideal blackbody sources at $318 \mathrm{~K}$ (top curve) and $258 \mathrm{~K}$ (bottom curve). The corresponding dashed curves have an emissivity less than one, like the natural terrain. The shaded areas are the atmospheric windows that occur at wavelengths where the earth's radiation has the same slope as an ideal blackbody source; these are the wavelengths our GEM system will use. 
where $\lambda$ is the infrared wavelength in micrometres. Thus, for the 3.5- $\mu \mathrm{m}$ band, the emittance varies as the 14 th power of the temperature. Third, with the GEM system we can avoid those IR wavelength regions in which the interpretation is subject to uncertainties larger than about $2 \mathrm{~K}$. Such large uncertainties are associated with wavelengths at which the terrain radiates as a specular source; i.e., the surface emissivity varies greatly with wavelength. This occurs for minerals containing certain anions, such as silicate, sulfate, and carbonate.

Figure 1 indicates the wavelengths at which the earth's radiation (dashed curves) has the same slope as that of an ideal blackbody source (solid curves). The shaded bands are the atmospheric windows that avoid wavelengths at which the terrain behaves as a specular source. These windows are the wavelengths our GEM system uses. Signal ratios of bands at these wavelengths can be used to resolve $0.05-$ to $0.5-\mathrm{K}$ temperature rises over areas larger than $1 \mathrm{~km}^{2}$.

To enhance the detectability of geothermal anomalies, several procedures need to be followed:

- Aerial surveys should be taken when environmental conditions do not obscure geothermal anomalies.

- The temperature data must be corrected for minor emissivity effects, reflected sky radiation, and the intervening atmospheric path.

- Thermal anomalies identifiable with meteorological, hydrological, topographical, or soil thermal conditions must be removed from the data.

We have developed a methodology that will perform these tasks.

For optimum measuring conditions the aerial surveys should be taken before dawn, when the earth has reached a diurnal equilibrium temperature and the wind velocity is most likely to be suitably low (less than $1.3 \mathrm{~m} / \mathrm{s}-3 \mathrm{mph}$ ). This enhances the thermal contrast originating from effects.

To distinguish between the anomalies associated with surface emissivity variations and those associated with geothermal activity, we use an emissivity-dependent function obtained from the multiband IR data. To correct for the intervening atmospheric path and reflected sky radiation, we determine the air temperature at the surface and sensor altitudes, the relative humidity, and the cloud-cover conditions.

Thermal anomalies associated with meteorological, hydrological, topographical, and soil thermal conditions can be calculated. To do this we simulate the surface temperatures (assuming no geothermal activity) using a digital surface-climate model that accounts for the effects of some 15 measurable environmental parameters. 1

In geothermal areas, temperature anomalies of 0.05 to $0.5 \mathrm{~K}$ above ambient would appear as a residual difference between the measured-and-corrected surface temperatures and the surface temperatures calculated using the surface-climate model. These low-level temperature differences, unlike climatic anomalies, would change very little from season to season and be relatively independent of the topography. Geothermal anomalies would represent an above-average temperature over an extended area - a few tens to a few hundreds of square kilometres. This is a spatial-thermal effect encompassing a relatively large area, the geothermal resource area. It is thus distinguishable, using signal-processing techniques, from the spatial effects covering smaller areas.

We have made preliminary tests of our data-analysis method using extant dual-band IR data recorded in narrow IR bands entered near 5 and $10 \mu \mathrm{m}$. These data were taken by the National Oceanic and Atmospheric Administration (NOAA) over vegetated terrain in upstate New York. We found, for this area, that the ratios of the signals recorded at the two bands had the desired properties: they were insensitive to surface emissivity variations, varied nearly as the fifth power of the surface temperature, and could be used to isolate emissivity-related effects.

Working with the Development and Resources Transportation Company (Silver Spring, Maryland), we were able to characterize the observed surfacetemperature variations and separate out the purely emissivity-related features of the terrain. With three input parameters - the $5 \cdot \mu \mathrm{m}$ signal, the emissivity ratio, and the soil moisture of 34 ground samples we performed a cluster analysis (a statistical method), which showed that the raw radiant-emittance data fell into two distinct terrain groups. An independent test showed that this dichotomy was based on the condition of the surface vegetation; one group was characterized by dry, dying vegetation and the other by viable, green vegetation.

Using corrections based on this cluster analysis, we adjusted the airborne radiant-temperature measurements at $10 \mu \mathrm{m}$ for surface emissivity variations, reflected sky radiation, and the intervening atmospheric path. We then compared the corrected surfacetemperature data with the calculated values obtained using the surface-climate model. The calculated mean 
surface temperatures, $291.87 \mathrm{~K}$ for the dry vegetation and $291.61 \mathrm{~K}$ for the green vegetation, differed by only 0.01 and $0.15 \mathrm{~K}$, respectively, from the measured mean surface temperatures.

The natural temperatures at various locations on the test terrain at the time the NOAA data were taken varied from the mean temperature by as much as $2 \mathrm{~K}$. However, we were able to discern that the mean temperature for the part of the terrain that lay at an altitude of $370 \mathrm{~m}$ was $0.2 \mathrm{~K}$ colder than the $290-\mathrm{m}$ part. (This difference results mostly from the normal temperature drop with increasing altitude.) This topographical effect was distinguishable as a large-area, low-magnitude correction that was separable from temperature variations that had a larger magnitude but covered a smaller area.

A cooperative project is being proposed by LLL, the Environmental Research Institute of Michigan (Ann Arbor), and Ensco, Inc. (Springfield, Virginia) to test the feasibility of our GEM system for geothermal resource investigations. This joint venture will make use of a modification of the LLL multiband instrumentation concept to evaluate aerial surface temperature measurements over several nongeothermal areas in Michigan. LLL will provide the major technical direction. Selected test areas will be measured by aerial and surface radiometric methods. The results will be compared with temperatures calculated using our model and with contact-temperature data taken at the surface and at shallow depths. If the results are as encouraging as those of the analysis of the New York NOAA data, we hope to be able to proceed with a full-scale effort to develop our aerial reconnaissance method as a routine geothermal prospecting technique.

Key Words: aerial infrared surveys; geothermal energy multiband system; GEM; geothermal power resources; radiant emittance; surface emissivity; infrared radiation - measurements; thermal radiation. 


\title{
ENVIRONMENT AND SAFETY
}

\author{
SEISMIC RESPONSE ANALYSIS OF A NUCLEAR FUEL FABRICATION PLANT
}

LLL recently evaluated the structural integrity of mixed-oxide fuel fabrication plants (MOFFP) subjected to seismic intensities ranging from 0.98 to $9.8 \mathrm{~m} / \mathrm{s}^{2}$ ( 0.1 to $1.0 \mathrm{~g})$ peak ground accelerations. The study was requested and funded by the U.S. Nuclear Regulatory Commission, Office of Standards Development. At a MOFFP, plutonium and uranium oxides recovered from spent reactor fuel elements are made into new fuel elements. The radiological hazards of both oxides necessitate careful risk assessment in plant siting.

We developed calculational models of the MOFFP building and interior safety-related systems: glove boxes and gloved barriers, the plutonium-oxide storage bins, and the ventilation system. Our primary emphasis, however, was on the main structural components of the plant building. The completed study provides a technical basis for assessing the environmental impact and public risk associated with MOFFP siting.

At the request of the U.S. Nuclear Regulatory Commission's Office of Standards Development, the Laboratory conducted a seismic response analysis of a nuclear fuel fabrication plant. We evaluated the structural integrity and potential failure modes of a MOFFP subjected to seismic intensities ranging from 0.98 to $9.8 \mathrm{~m} / \mathrm{s}^{2}(0.1$ to $1.0 \mathrm{~g})$ peak ground accelerations. This range includes any strong ground motion that might reasonably be expected.

At a MOFFP, plutonium and uranium oxides recovered from spent reactor fuel elements are made into new fuel elements for light-water-cooled reactors. The plutonium and uranium oxides enter the plant's manufacturing building in powder form and are weighed and blended. They are then milled, pressed, sintered, ground, cleaned, and loaded into fuel rods. The MOFFP of the future (10 to 15 years hence) is expected to produce about 1 tonne of mixed-oxide fuel per day. This fuel will contain 2 to $4 \%$ by weight of plutonium oxide, the remainder being uranium oxide.

The presence of plutonium and uranium oxides at MOFFP's necessitates careful risk assessment in plant

Contact Frank J. Tokarz (Ext. 8906) for further information on this article. siting. Because plutonium presents a much greater radiological hazard than uranium, we concentrated on earthquake-induced accidents in plutonium processes. The tasks of our study were threefold:

1. Develop calculational models for the main structure and safety-related systems of a typical commercial-scale MOFFP.

2. Define ground motion to be used in response analysis.

3. Perform elastic and inelastic dynamic response analyses on the main structure and identify failure modes associated with different ground motion intensities.

Our completed study provides a technical basis for assessing the environmental impact and public risk associated with MOFFP siting.

\section{Calculational Models}

The safety-related structure and systems of the MOFFP are the main structural components of the fuel plant building, the glove boxes and gloved barriers, the plutonium-oxide storage bins, and the ventilation system. Our study emphasized the main structural components, although we also examined the other systems.

Most MOFFP's expected to be built in the next 30 years will be located east of the Continental Divide near fuel reprocessing plants and nuclear power reactors. Seismic design criteria in this area use peak ground motion levels in the $0.98-$ to $1.9-\mathrm{m} / \mathrm{s}^{2}$ range. Because tornado design criteria are much more stringent, they generally govern the external structural design. Seismic design criteria are usually used for internal structure, equipment, and piping. Our model plant building is designed for an eastern facility; MOFFP's built west of the Continental Divide will be considered on a case-by-case basis.

Building Structure. Our model fuel fabrication plant is a two-story structure with work areas as shown in Fig. 2. Areas where plutonium is in powder form are enclosed by a restricted-access barrier to form the "canyon," which extends from the first floor to the roof. The building is $64 \mathrm{~m}$ square with $460-\mathrm{mm}$-thick reinforced concrete roof, floors, and walls. The structure does not extend below grade. 


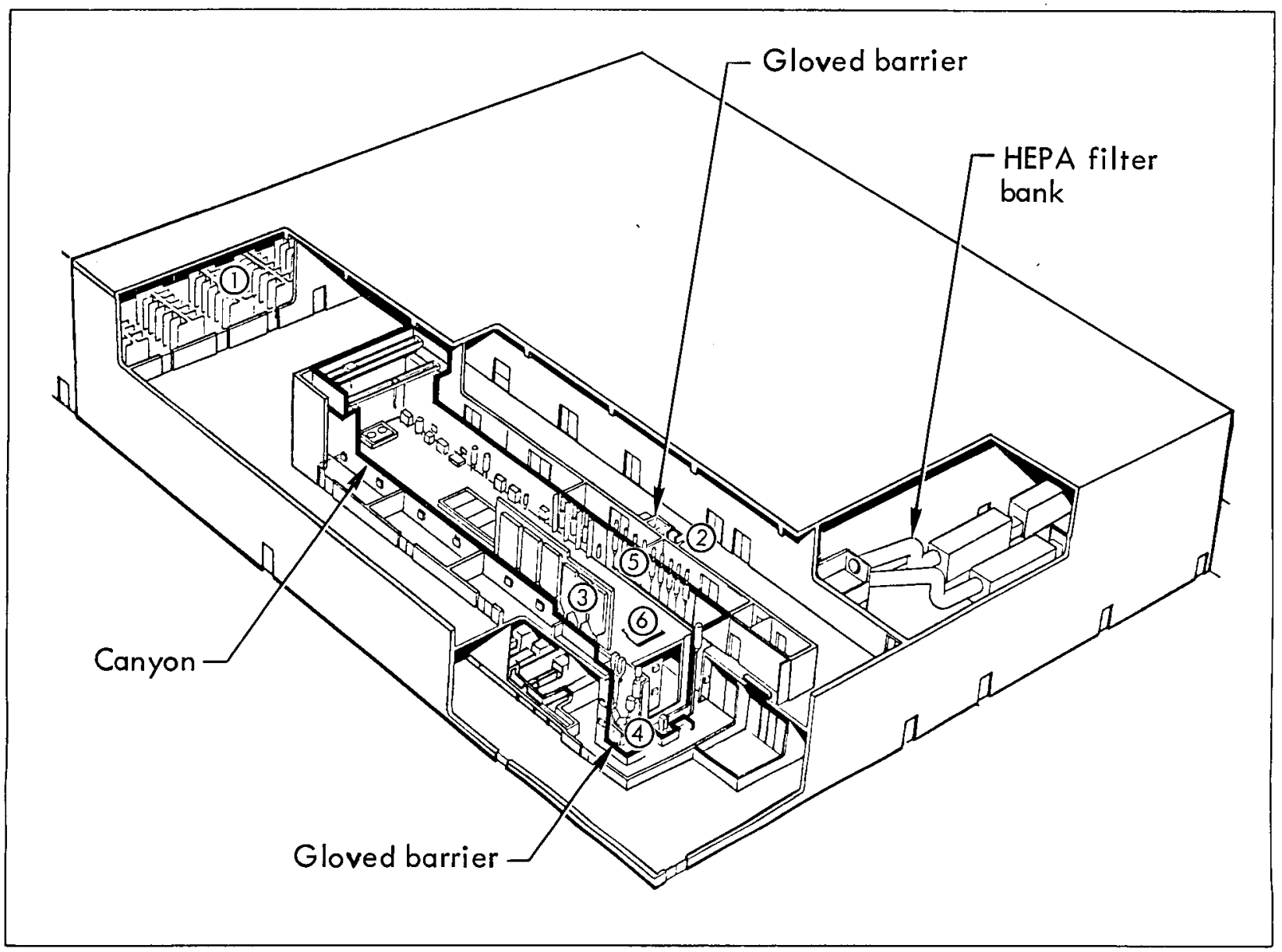

Fig. 2. Model of a typical plant building. The plutonium and uranium oxides are received and temporarily held in their shipping containers (1). The containers are then moved to the unloading station (2), where their contents, in powder form, are transferred to bulk storage bins (3). From these bins the powders are weighed and mixed in the blending column (4) and are sent to mixed-oxide storage (5). They are then compacted, granulated, and pressed into pellets in the pressing column (6). The remaining processes, in which the oxides are not in dispersible powder form, take place in other parts of the building.

The vertical load-carrying system consists of slabs spanning supporting edge beams that bear on 610 $\times$ 610-mm columns on 9-m centers each way. At end bays, the exterior walls act as bearing walls. The lateral force-resisting system consists of floor and roof slabs and shear walls. The slabs act as rigid concrete beams spanning exterior shear walls, which are parallel to the direction of applied forces. The shear walls act as braces, transmitting the loads to the foundation.

The roof and walls of our model MOFFP are designed for $24-\mathrm{kPa}$ tornado loading. The roof is considered a slab that distributes the load in both horizontal directions; the walls are treated as slabs that distribute the load between the floor and/or roof levels. The floors and columns are designed for $19-\mathrm{kPa}$ floor loading. The floor is treated as a two-way slab and the columns as doubly reinforced tied members.
Equipment. To examine equipment response, we generated floor spectra and maximum floor accelerations for a model building constructed on a hard site. We found the maximum floor acceleration to be less than twice the maximum ground acceleration. A review of representative equipment in the building indicated that with proper design and location of attachments, the equipment will be sufficiently rigid (i.e., there will be no amplification) for its maximum acceleration to be the maximum floor acceleration.

All processes in which plutonium-oxide powder could pose an inhalation hazard are performed in glove boxes or gloved barriers. Experience at LLL shows that this safety equipment can stand floor acceleration levels greater than $9.8 \mathrm{~m} / \mathrm{s}^{2}$. Penetration of a glove box will require objects heavier than $45 \mathrm{~kg}$. Such 
objects (e.g., concrete chunks) are not available before total collapse of the building.

Plutonium-oxide powder is stored in bins designed to receive powder from the transfer system while avoiding criticality conditions. Each bin is supported by two seats with four braces for lateral support. The resistance of the bin to seismic motions will be governed by the adequacy of the supports. Estimates of support requirements indicate that braces can be designed to handle seismic loads resulting from acceleration of many metres per second per second.

In the MOFFP model, air flow is always in the direction of greater radioactive contamination potential. High-efficiency particulate air (HEPA) filters are used to minimize the release of airborne plutonium oxide. Air is filtered when it enters the plant, when it enters glove boxes and gloved barriers, when it leaves the work areas, and when it leaves the building through a final double-HEPA filter bank.

We restricted our examination of the ventilation system to the final HEPA filter bank. ORNL-NSIC-65 guidelines $^{2}$ state that (1) the HEPA filter frame must be designed to carry a $13.8-\mathrm{kPa}$ shock loading across the bank without exceeding the elastic limit of the material, and (2) the maximum member deflections must be limited to $0.1 \%$ of their length under a loading equivalent to 1.5 times the maximum dirty-filter pressure drop across the bank. Since these criteria are more stringent than seismic criteria, they govern the design. We judge that the structural integrity of the final HEPA filter frame is such that floor acceleration levels greater than $9.8 \mathrm{~m} / \mathrm{s}^{2}$ are required to cause failures.

We did not perform an extensive structural analysis of ventilation ducting and utility piping. Failure would most likely result from falling objects or excessive relative displacements between anchor points, neither of which should occur until total building collapse.

\section{Input Ground Motion}

To define the input ground motion for our model MOFFP, we used the procedure described in U.S. AEC Regulatory Guide 1.60 (Ref. 3). Guide 1.60 defines the seismic input to nuclear power reactors based on a statistical treatment of some 50 earthquake records. It is intended for sites on either rock or soil deposits and gives horizontal and vertical response spectra for all frequencies of interest. Once the maximum horizontal ground acceleration is specified (in our case, $9.8 \mathrm{~m} / \mathrm{s}^{2}$ ), response spectra can be defined from Guide 1.60 simply by scaling.
In addition to specifying response spectra, we synthesized horizontal and vertical accelerograms that reflected the frequency content of the response spectra. To develop the accelerograms, we selected a 30 -s record with 10 to $15 \mathrm{~s}$ of strong shaking. We believe that these parameters represent the ground motions of large earthquakes.

\section{Response Analysis of Main Structure}

Our structural response analysis of the model building included dynamic elastic and inelastic response analyses for both the horizontal and vertical directions. The elastic analyses used the acceleration response spectra directly; the inelastic analyses used the synthetic accelerograms.

Horizontal Analyses. For the elastic analysis, we used a lumped mass model to capture the horizontal response characteristics of the building. The mass of the building was distributed to the roof, second floor, and first floor. Lateral resistance of the shear walls was represented as shear springs. Their values reflect the shear resistance of the reinforced concrete walls parallel to the direction of the motion. Elastic unloading was assumed.

We also used soil-structure spring constants in the elastic analysis to include the possibility of soil-structure interaction effects. The soil springs reflect shear-wave velocities consistent with hard, intermediate, and soft sites. The most valuable result from the elastic horizontal-response calculations was that we established trends in response variations as a function of possible soil-structure interaction effects. The response characteristics for hard, intermediate, and soft sites vary considerably.

For the inelastic analysis, we used the same calculational model but included a maximum lateral load capacity consistent with the ultimate shear-stress capacity of the walls with web reinforcement. We assumed that the horizontal temperature and shrinkage reinforcement also acted as web reinforcement. Our results are given in Table 1 . For a ground motion of $4.9 \mathrm{~m} / \mathrm{s}^{2}$, the maximum roof displacement was $3.3 \mathrm{~mm}$. At $7.8 \mathrm{~m} / \mathrm{s}^{2}$ and greater, deflections of $75 \mathrm{~mm}$ and more were calculated.

Vertical Analyses. Our model for the vertical load-carrying resistance of the building represented the second floor and roof slabs as beams spanning columns at interior bays and spanning to the walls at the exterior bays. The columns and walls were treated as beam-column elements. 
Table 1. Damage predictions from inelastic horizontal analysis Ground motion
level
$\left(\mathrm{m} / \mathrm{s}^{2}\right)$ Location

\section{$<4.9$}

4.9-5.9

7.3-7.8
No damage

First floor shear wall

Second floor shear wall leading to total collapse

Moments of inertia were based on gross concrete sections. We developed member-yield criteria using ultimate strength design concepts and a review of experimental data on failure of reinforced concrete members. The mass of the building was distributed uniformly at the roof and floor levels.

The elastic response analysis of the building indicates that maximum roof and second floor deflections for a $9.8-\mathrm{m} / \mathrm{s}^{2}$ earthquake with static dead and live loads included are 5.8 and $4 \mathrm{~mm}$, respectively. For a $3.9-\mathrm{m} / \mathrm{s}^{2}$ vertical ground motion, values are 4.8 and $3.6 \mathrm{~mm}$.

Results from the inelastic vertical analysis are given in Table 2. Above $5.4 \mathrm{~m} / \mathrm{s}^{2}$, deflections at the midspan of both the roof and second floor slabs exceed $250 \mathrm{~mm}$.

Discussion

Our horizontal inelastic response analysis for MOFFP's founded on hard sites shows that below a

Table 2. Damage predictions from inelastic vertical analysis

\begin{aligned} $\begin{array}{c}\text { Ground motion } \\ \text { level } \\ \left(\mathrm{m} / \mathrm{s}^{2}\right)\end{array} & \multicolumn{1}{c}{$ Location } \\ \hline$<3.9 &$ No damage \\ 3.9 & Innermost columns \\ 4.9 & Roof slab, some of second floor \\ 5.4 & All slabs and columns \\ $>5.4 &$ Total collapse \end{aligned}

maximum horizontal ground acceleration of $4.9 \mathrm{~m} / \mathrm{s}^{2}$, the main building suffers no appreciable damage (i.e., no extensive cracking). At $7.8 \mathrm{~m} / \mathrm{s}^{2}$ and greater, the total lateral resisting capacity of the building is exceeded and the building collapses. However, if we extrapolate from the elastic response analysis, which includes soil-structure interaction effects, total building collapse from lateral motions occurs between 4.9 and $5.9 \mathrm{~m} / \mathrm{s}^{2}$ ground accelerations.

Analysis of inelastic vertical motions shows that roof slab damage occurs at about $3.9 \mathrm{~m} / \mathrm{s}^{2}$, that the floor slab and most of the roof slab undergo plastic deformation at 4.9 to $5.4 \mathrm{~m} / \mathrm{s}^{2}$, and that total collapse occurs above $5.4 \mathrm{~m} / \mathrm{s}^{2}$.

We thus concluded that the conservative limits to structural integrity for the model MOFFP we developed are:

- No structural damage at ground motions less than $3.9 \mathrm{~m} / \mathrm{s}^{2}$.

- Moderate to severe structural damage at 3.9 to $4.9 \mathrm{~m} / \mathrm{s}^{2}$.

- Complete building collapse at greater than $4.9 \mathrm{~m} / \mathrm{s}^{2}$.

Our examination of equipment in the building showed that it appears to have structural integrity to resist vibratory motions with peak floor accelerations greater than $9.8 \mathrm{~m} / \mathrm{s}^{2}$. We would anticipate failures of the ventilation ducting and utility piping only in conjunction with major failure of the main building structure.

It is important to remember that most future MOFFP's will be designed primarily to tornado criteria, as was our own MOFFP model. Such MOFFP's typically will have to withstand ground accelerations of 0.98 to $1.9 \mathrm{~m} / \mathrm{s}^{2}$. In the case of a MOFFP built where seismic design criteria are overriding (i.e., west of the Continental Divide), minimum structural modifications will make the building capable of carrying ground motion levels exceeding $9.8 \mathrm{~m} / \mathrm{s}^{2}$.

Key Words: seismic response; seismic effects - numerical analysis; dynamic response analysis; inelastic seismic response; design criteria - seismic; design criteria - tornado; reactor fuels - fabrication; fuel cycle facilities; fuel fabrication plants; environmental impact; risk assessment - plant siting; radiation safety. 
The radioactivity in uranium mines, due mainly to radon gas and its particulate daughters, poses a serious health hazard for miners. To reduce this hazard, the U.S. Bureau of Mines is now evaluating the feasibility of coating the mine walls with a sealant to impede circulation of the gas and this prevent dispersion of the daughters. We recently completed a study for the Bureau in which we developed preliminary criteria for evaluating potential sealants and examined specific sealants for toxicity during application or during a fire.

Studies have shown that the incidence of lung cancer among uranium miners is much higher than among the population at large and that it is directly related both to radioactivity concentration and exposure time in the mines. ${ }^{4}$ Lung-cancer mortality among the miners, as compared with the general public, rises to ratios of

The exterior and interior photographs of uranium mines shown in the frontispiece, $p$. iv, are courtesy of Deane Smith, State College, Pennsylvania. The exterior shot, taken in 1952, is of the Delta Mine in central Utah. The interior shots, all flashbulb photography, are from the Mivida and Happy Jack uranium mines.

20:1 and even higher with increasing concentrations and exposure times. The problem, already a serious concern, will be compounded as we strive to double our annual uranium output in response to predicted needs. $^{5}$

The main source of radioactivity in the mines is the radon gas that continuously evolves from uranium ore. Because of its short half-life ( 3.82 days), the gas soon decomposes into alpha-emitting daughters that collect on the mine dust, entering the miners' lungs. Massive ventilation is the only effective way at present to reduce the hazard. However, the Bureau of Mines is now investigating the feasibility of mine-wall sealants that are sufficiently impermeable to radon to hold the gas until it decays into particulate daughters. Thus trapped, the daughters are prevented from dispersing into the mine atmosphere.

The Laboratory was asked to assist in the Bureau's investigation. In a recently completed study, ${ }^{6}$ we evaluated selected uranium sealants as radon barriers, first on their effectiveness in reducing radon

Contact H. George Hammon (Ext. 86l0) for further information on this article. permeation and second on the basis of their potential toxicity during application or in a mine fire. We developed a method of estimating radon permeation coefficients from the permeation coefficients of other noble gases. We also related the permeation coefficients of argon, krypton, xenon, and radon to the structure of sealants' base polymer.

Sealant Selection and Preparation

The first step of our study was to select and prepare sealants with which to work. They were chosen on the basis of known chemical composition from commercially available polymers. We used three epoxy compositions (two unpigmented and one pigmented), a furan coating, a one-component polyester, and vinylidene chloride copolymer latexes. Thin films of these sealants were made on a polyethylene ionomer substrate with high permeability and better wetting characteristics than conventional polyethylene.

For the toxicity studies, we applied some sealants to the surface of cement-asbestos board specimens for examination when subjected to heat and fire. To ensure that the sealants behaved the same on cement-asbestos board as they would on uranium ore, we made a few specimens on low-grade uranium ore and compared results. Behavior was essentially the same, and we were able to proceed with the cement-asbestos specimens.

\section{Determination of Permeation Coefficients}

To determine the permeation coefficients of the noble gases, we relied on two techniques: a sensitive method using a mass spectrometer as a gas detector and a Dow film permeability cell. We also determined radon permeation directly using equipment built especially for that purpose.

In the mass spectrometer method, a thin film (up to $380 \mu \mathrm{m}$ ) of sealant forms a membrane in a specially designed permeation cell. The cell is evacuated on both sides of the membrane until the gas background is negligible. The test gas is then applied at a known pressure on one side of the membrane. Permeation of the test gas through the membrane is compared to a known, constant flow of the same gas. From this information, we calculate the permeation rate. Knowing the pressure differential across the membrane and the membrane's thickness and area, we then determine the permeation coefficient. 
This method is efficient and accurate. Interfering membrane outgassing and desorption gases can be distinguished from the test gas, and pinholes in or leaks around the membrane are readily recognized. However, the technique is time consuming for films of low permeability or for higher-molecular-weight gases such as krypton or xenon.

The Dow film permeability cell has the advantage of greater speed because it uses larger films and has a greater pressure differential. A film is clamped with an O-ring against a permeable surface. There is a vacuum below the surface, and the test gas is introduced above at a known pressure. The rate of gas permeation is measured by the rate of change on a manometer below the sample.

Permeation measurements are more difficult for radon than for the other noble gases. Because of its large gas molecule and slow diffusion rate, radon's permeation rate is slow. Yet its short half-life means that radon deposits its daughter products in the measuring apparatus. Nevertheless, for comparison purposes, we measured radon permeation through polyethylene and polycarbonate films, using apparatus made especially for the purpose from glass tubing. The apparatus was divided into two chambers by a thin film, and radon from a radium solution was admitted to one side. The gas that permeated the film to the other side was measured by alpha counting.

Our noble-gas measurements showed that it is possible to make a straight-line extrapolation of the permeability data, especially for argon, krypton, and xenon, when the logs of the permeation coefficients are plotted against the square of the gas molecular diameter. From this extrapolation, we can estimate the radon permeation coefficient.

Figure 3 shows permeability data for six of the sealants we evaluated, with the straight-line extrapolation in each case. Note that the direct measurements of the radon permeation coefficients on polycarbonate and polyethylene agree well with the values that would be predicted by extrapolation from argon, krypton, and xenon. In general, the helium and neon permeation coefficients did not fit well with the other data.

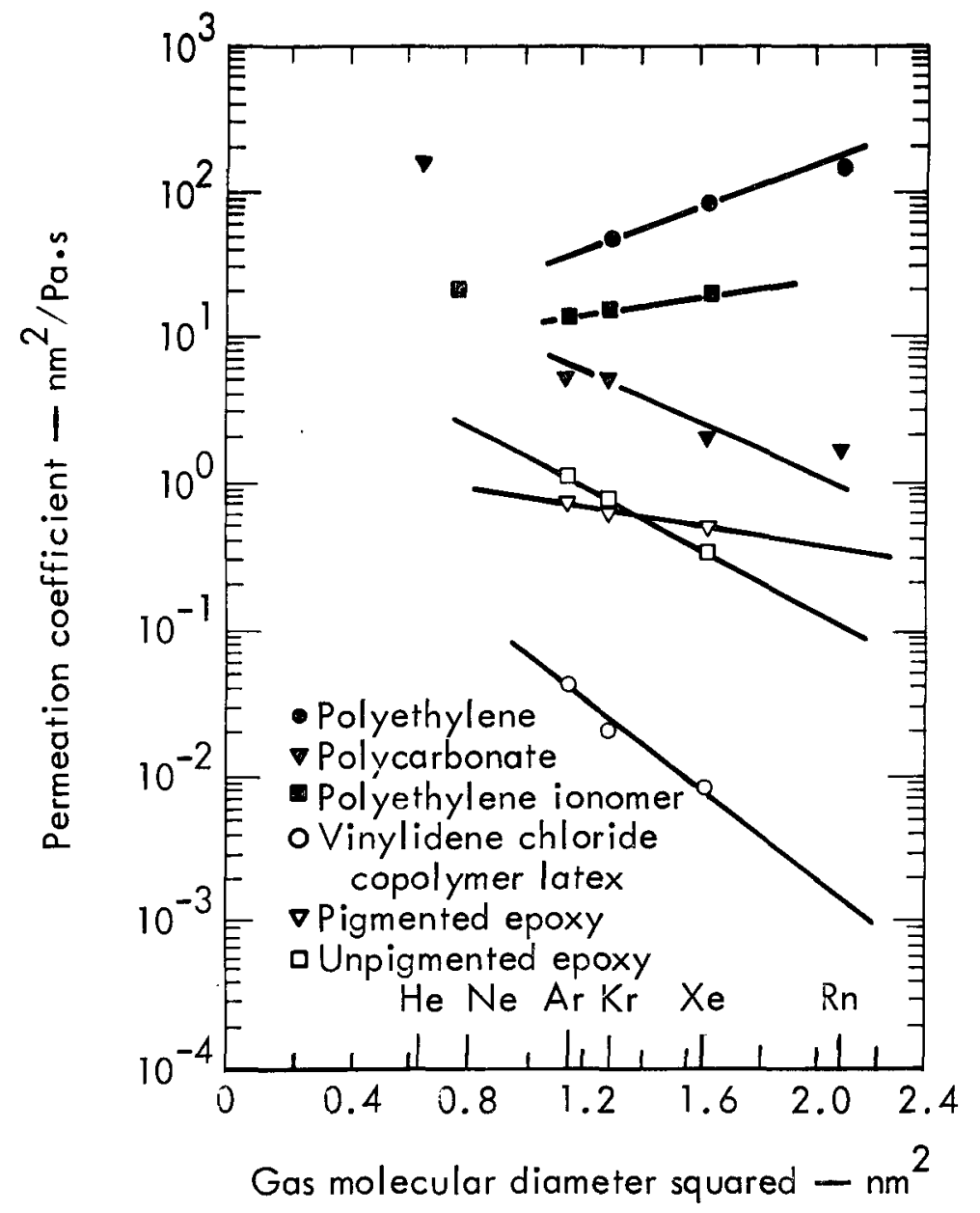

Fig. 3. Permeation coefficient results for three sealants and three polymer films. The data have been extrapolated to permit estimation of the radon permeation coefficient. Agreement between estimated radon permeation coefficients and those measured directly (on polycarbonate and polyethylene coatings) is good. Most helium and neon data are not shown. 
Correlation of Permeability with Polymer Structure

It would be helpful in selecting sealants as radon barriers if we could predict radon permeation as a function of the structure of the sealant's base polymer. Many chemical, morphological, and structural properties of the polymer can affect its permeability. After examining several of these properties and eliminating them from consideration, we found a correlation between the noble-gas permeation of a number of polymers and the oxygen Permachor equation developed by Salame. (The oxygen Permachor is a numerical description of polymer structure obtained by assigning numerical values to its parts. ${ }^{7}$ ) Because the oxygen Permachor is related to the structure of the polymer, we were able to develop an equation that related noble-gas permeation coefficients to polymer structure. The equation can be used to estimate the permeation of radon, as well as the other noble gases, through polymers.

\section{Toxicity Evaluation}

For use in a mine, sealants should be nontoxic during application, and their combustion and pyrolysis products should be of low toxicity. To examine our sealants for toxicity during application, we identified their volatile fractions using gas chromatography and mass spectroscopy. The only materials of toxicological significance were vinylidene chloride (a suspected carcinogen) in a copolymer latex, and vinyl chloride (a carcinogen) and epichlorohydrin (a sensitizer) in an unpigmented epoxy. These materials would be reduced to acceptably low concentrations with normal mine ventilation.

We evaluated the combustion and pyrolysis products in two ways. We studied the cement-asbestos boards in a smoke chamber and conducted small-scale laboratory pyrolysis studies of unsupported films. In the smoke chamber studies, the unpigmented epoxy sealants developed dense smoke when exposed to heat or fire. The pigmented epoxy produced only light smoke and no toxic components in the vapors. The furan developed negligible amounts of smoke but had an objectionable odor; its black color might also be undesirable. The one-component polyester produced only light smoke but would be hazardous when applied because of its low flash point, which results from a high styrene content. The vinylidene chloride copolymer latexes yielded large amounts of hydrogen chloride when exposed to heat or fire, but they produced negligible amounts of smoke.

The pyrolysis studies did not reveal toxic materials other than carbon monoxide and hydrogen chloride in significant quantities. Carbon monoxide was not generated from any of the sealants' in amounts that would be large compared to those resulting from other materials involved in a mine fire, such as wood, diesel fuel, and waste materials.

\section{Conclusions}

Our study showed that it is possible to estimate radon permeability through various mine-wall sealants by extrapolating from measured coefficients of other noble gases, particularly argon, krypton, and xenon. For a first-cut selection of potential sealants, we developed an equation that can be used to predict radon permeability as a function of the coating's base-polymer structure. Our toxicity studies provided initial information about possible side effects from a number of basic sealant classes.

Key Words: radon; radon permeation; radiation safety; uranium mining; permeability - measurements; polymers -permeability; sealants; noble gases; smoke chamber. 


\title{
SCIENCE AND TECHNOLOGY
}

\author{
COMPUTER-CONTROLLED MULTIPLE-ACTUATOR SHAKER \\ OFFERS UNIQUE TEST CAPABILITIES
}

The Laboratory's multiple-actuator shaker facility at Site 300, developed for weapons testing, is now also being used for such studies as shock and vibration tests of rocket motors, seismic qualification of a turbine-generator set, and performance analysis of the rock bolts used in mine-tunnel construction. Rigid loads exceeding 9 tonnes can be tested over a wide frequency range (dc to $500 \mathrm{~Hz}$ ) with up to 120 channels of real-time data acquisition and display. Capabilities include the safe testing of hazardous materrials and explosives exceeding $90-\mathrm{kg}$ TNT equivalent. The computerized control system permits the shaker to be easily adapted to nonstandard shock and vibration tests. We envision the shaker being used for a wide variety of projects such as materials testing, aerospace structural-response studies, seismic proof testing, and conventional ordnance work.

Development of the shaker facility at Site 300 , near Livermore, began in July 1968 in response to weapons-program requirements for a high-force, high-amplitude, low-frequency shock and vibration test capability. The first stage of construction was completed in the fall of 1970 , when a $0.62-\mathrm{MN}$-thrust electrohydraulic shaker with four portable, base-mounted actuators was brought on line under an interim analog control system. A year later we began developing the digital-computer control system ${ }^{8}$ that now operates the facility. Various technical problems have been solved, such as actuator cross-coupling (undesirable responses of one actuator to the motions of the other actuators). The facility is now unique in its sophistication, versatility, and test capabilities.

\section{Test Facility}

As shown in Fig. 4, the test facility consists of three units: a control building for the data-acquisition and control equipment, an equipment building for the hydraulic power supply, and the test cell in which the shaker is located. The test cell, physically isolated from the control and equipment buildings, has sufficient overpressure design to permit safe testing of specimens

Contact Dennis K. Fisher (Ext. 8469) for further information on this article. exceeding 90-kg TNT equivalent. It also has air scrubbers and a containment system for radiation hazard control.

The hydraulic power supply consists of 11 individually controlled, pressure-compensated, 0.11-MW pumps running in parallel. Their combined continuous output is $0.043 \mathrm{~m}^{3} / \mathrm{s}(680 \mathrm{gpm})$ at a nominal supply pressure of $20.7 \mathrm{MPa}$. Peak flows to the four electrohydraulic actuators are $0.014 \mathrm{~m}^{3} / \mathrm{s}$ (225 gpm). We use a fire-retardant synthetic oil for safety purposes.

Each actuator has a maximum thrust capability of $0.155 \mathrm{MN}$ and a total stroke of $127 \mathrm{~nm}$. Integral hydrostatic guide bearings can support cross-axis loads up to $0.04 \mathrm{MN}$ without actuator damage. The high-performance, two-stage servovalves have a response time of $2.6 \times 10^{-4} \mathrm{~s}$, resulting in a nominal actuator bandwidth of $500 \mathrm{~Hz}$ and a peak velocity of $2 \mathrm{~m} / \mathrm{s}$. Stroke length, peak velocity, force output, and valve response combine to give the single-actuator performance characteristics shown in Fig. 5 .

Because the actuators are free-standing and relocatable, they can be bolted either to the top surface (for z-axis motion) or to the vertical abutments (for $\mathrm{x}^{-}$and $\mathrm{y}$-axis motion) of the 680-tonne, reinforced-concrete reaction mass. As shown in Fig. 6, threaded attachment sockets are provided for this purpose in the abutments and in the heavy steel plate that covers the reaction mass. This versatility gives us great latitude in fixturing (attaching a specimen to the actuators) and also in accommodating unusual specimen/actuator configurations.

In the most common test configuration (z-axis vibration), the actuators drive a rigid table to which the test specimen is secured. Two tables are available: a $3.8 \mathrm{~m}$ by $1.9 \mathrm{~m}$ unit weighing $1814 \mathrm{~kg}$ for four-actuator testing and a $1.6 \mathrm{~m}$ by $1.5 \mathrm{~m}$ unit weighing $640 \mathrm{~kg}$ for three-actuator testing. In both cases, the maximum clearance between the table surface and the overhead crane hook (9-tonne capacity) is $3.9 \mathrm{~m}$. By securing the actuators against the abutments and placing the test specimen on hydrostatic guide bearings, we can accommodate very massive specimens for $\mathrm{x}$ - or $\mathrm{y}$-axis testing (see Fig. 6). 


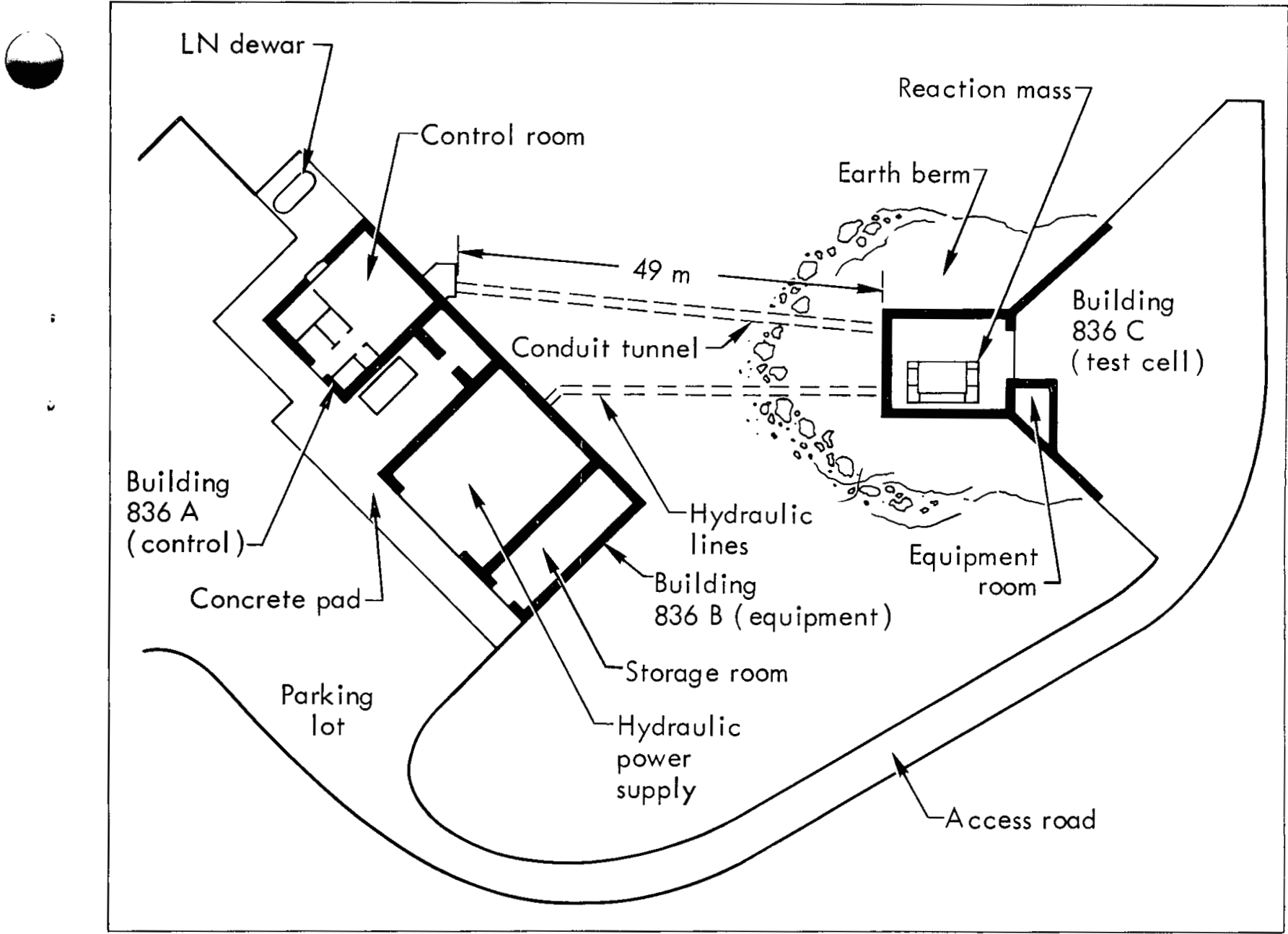

Fig. 4. Site 300 dynamic test facility.

We have installed a wide range of signal-conditioning and data-acquisition equipment. The general instrumentation equipment includes 24 channels of strain-gage conditioning, 12 channels of thermocouple reference junctions, 24 channels of dc differential amplifiers, and 24 channels of piezoelectric-transducer signal conditioners. Recording equipment includes a 32-track FM tape recorder and a 24-channel light-beam oscillograph. For unusual test requirements, we can easily integrate additional equipment into the system. In the past, as many as 120 data channels have been conditioned and recorded for a single test.

\section{Computerized Control System}

Figure 7 shows the configuration of the computerized control system. We have three hardware groupings: digital control hardware, hybrid interface components, and the analog process. The analog process can be either the actuators and test specimen (actual test hardware) or a dynamic simulation on a small, general-purpose analog computer. The simulation capability, originally needed for developing the computerized system, is now used for operator instruction and developing new-application software.

The command generation and data acquisition units (see Fig. 7) comprise the hybrid interface. The generation unit receives command data either directly from the computer or indirectly from the digital waveform synthesizer, which is used in sinusoidal-response testing to generate a repetitive waveform. Under control of the computer, the generation unit converts the digital commands to analog voltages, then combines, scales, and feeds the results to the actuator controllers. All four actuators can be commanded independently.

The data acquisition unit selects the appropriate response signals, converts them to digital form, and performs various preliminary data-processing functions. 
For each of the actuators, this unit can select the actuator displacement, load pressure, or associated specimen response as a feedback signal. The selected signal is scaled, filtered, sampled, and digitized with 12-bit precision at rates up to 50000 samples/s. The data can then be fed directly into the computer or, in the case of sinusoidal-response testing, further processed to yield peak, coincident, and quadrature components of response that are input after a slight delay.

The computer system is configured about a 16-bit-word-size central processor having 64000 words of 800-ns core memory, floating-point hardware, a $120-\mathrm{Hz}$ real-time clock, and an interval timer. Peripherals include a $1.2 \times 10^{6}$-word disk memory, seven-track magnetic tape unit, card reader, electrostatic printer, CRT graphics terminal and operator control console, and a hardware fast-Fourier-transform processor.
The control system operates as a closed loop, repetitively feeding response data to the computer from the acquisition unit and comparing the data with the desired test levels. New commands are computed and the results used to update the waveform synthesizer and/or command generation unit. The latter continuously feeds analog commands to each of the actuators, which in turn try to produce physical displacements in direct proportion to the command voltage levels. Appropriate transducers sense the resulting motion, returning the data to the acquisition unit to complete the loop.

Because of resonances in the table-specimen structure, the motion of one actuator may cause undesired responses at any other actuator. Historically, this cross-coupling has been a severe problem in multiple-actuator systems. A cross-coupled control system can be represented by a transfer matrix where the nonzero, off-diagonal terms are the cross-coupling.

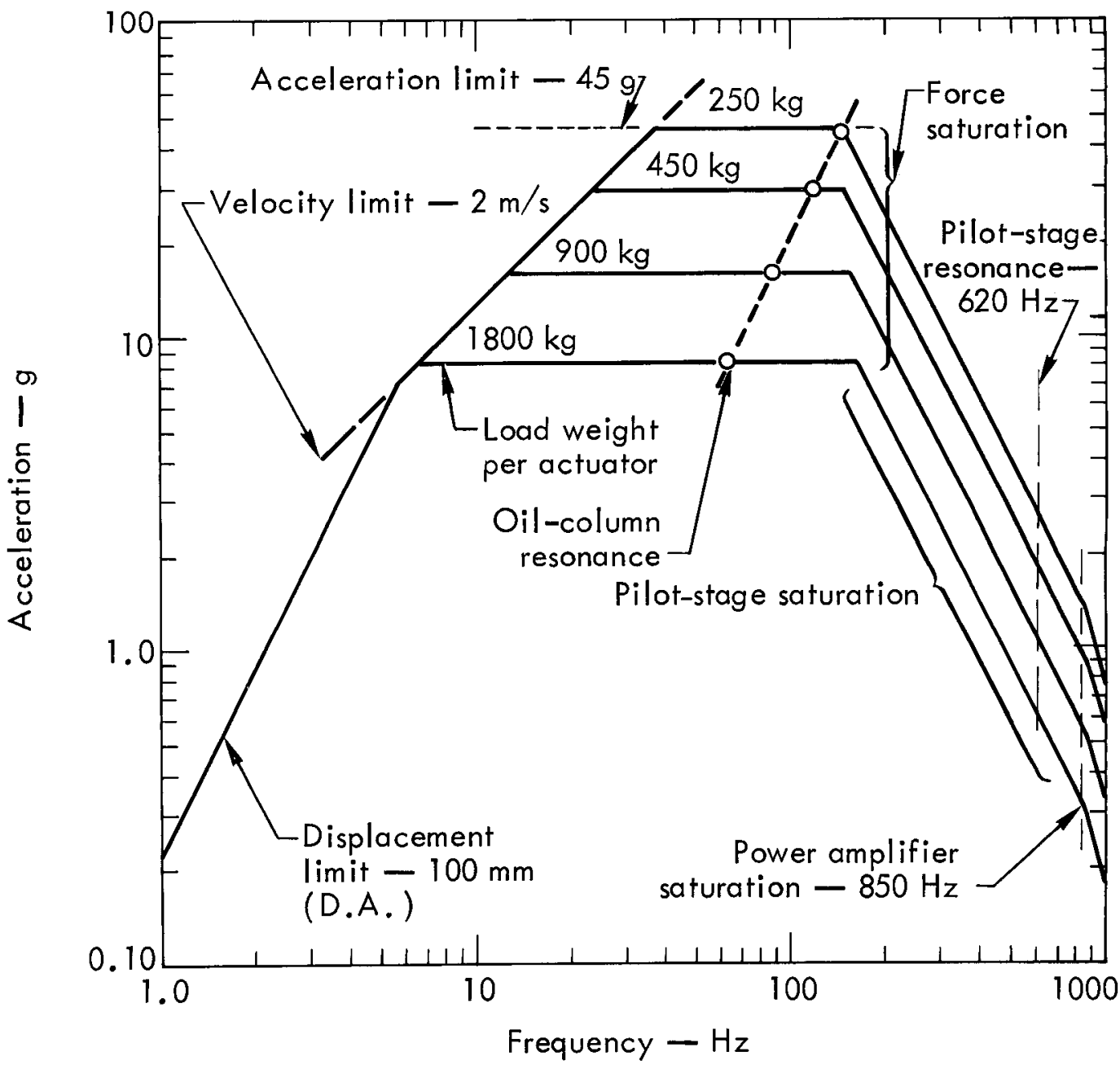

Fig. 5. Sinusoidal performance characteristics of a single actuator. 

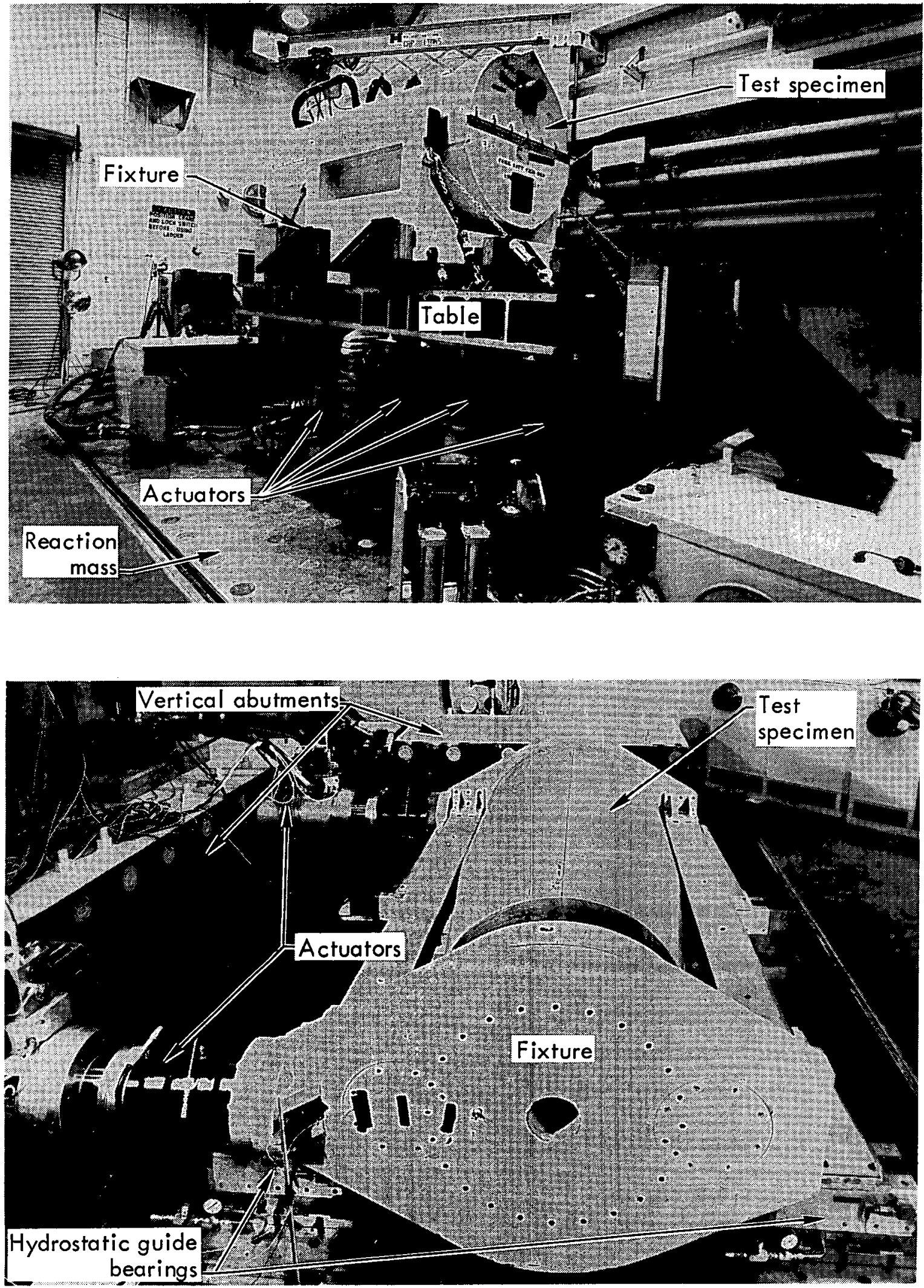

Fig. 6. Typical test configurations for z-axis motion (top), where the specimen is a shipping container, and y-axis motion (bottom), where the specimen is an upper-stage missile structure. 


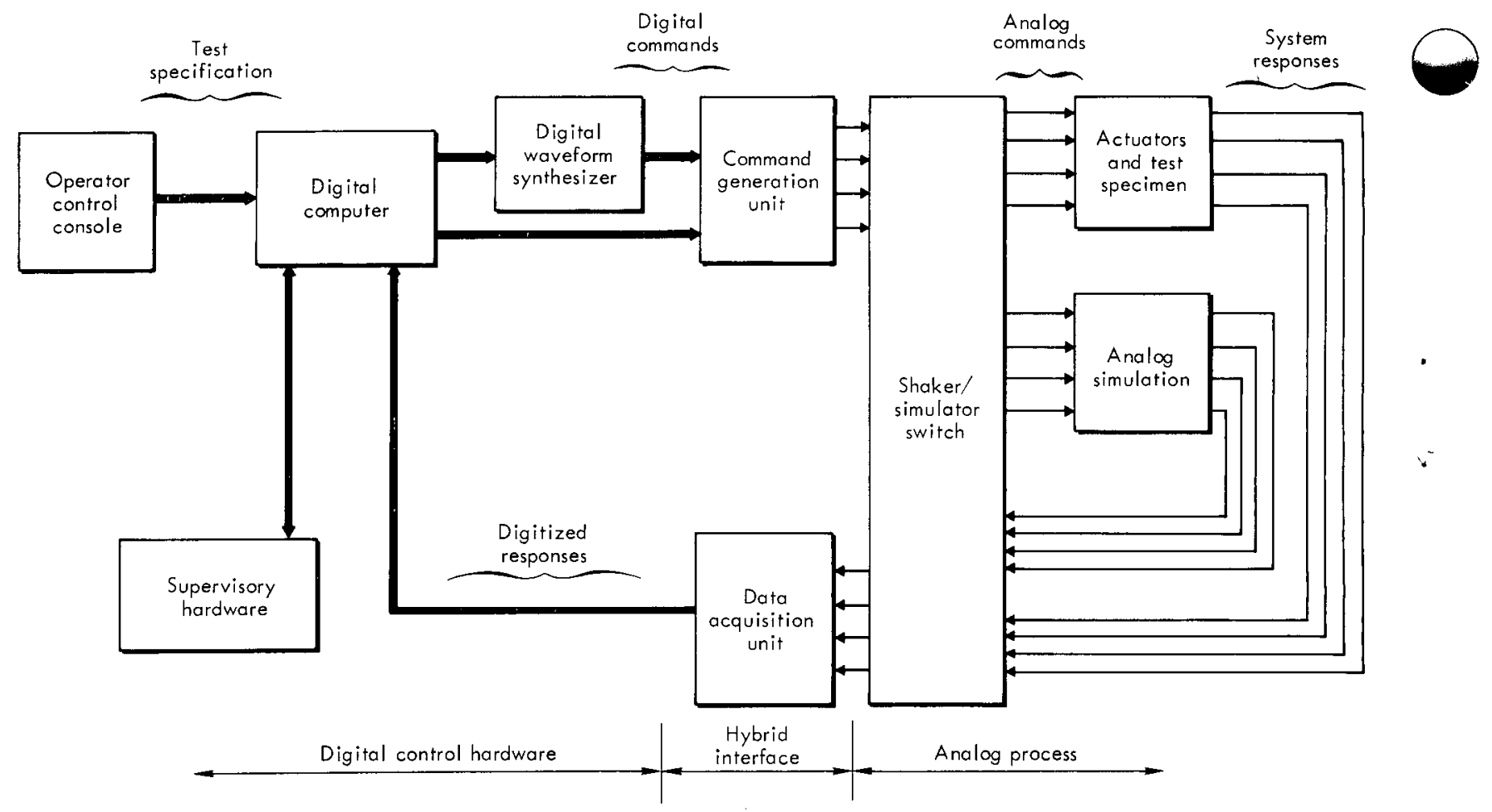

Fig. 7. Computer control system for the multiple-actuator shaker.

Ideally, we would like all the off-diagonal elements to be zero. To achieve this, we introduce a compensation matrix, which is simply the product of the desired system-transfer matrix and the inverse of the measured transfer matrix. By knowing the response characteristics of the system (in this case the combination of actuators, fixturing, and test specimen), we then calculate the input signals needed to produce the desired response. In essence, the actuators, to do one thing, are commanded to do another. ${ }^{9}$

Our new multiple-actuator control system is the first attempt to control cross-coupled actuators digitally. We have succeeded because (1) the system transfer matrix is determined by perturbation techniques at the full test level to minimize nonlinear effects and (2) general-purpose computer hardware permits the command compensation to be "tuned" to the system at an arbitrarily large number of frequencies. Thus implemented, our technique permits the same hardware to be used for a wide variety of tests.

\section{Test Capabilities}

Under computer control, the actuators are easily programmed to perform virtually any test within the fundamental mechanical/hydraulic performance limits defined in Fig. 5. General-purpose programs have been written for the most commonly performed tests. Each of these programs (see Table 3) features the CRT terminal and operator's console as the man-machine interface. By means of an interactive question-andanswer sequence, the operator defines the test to be performed. The test specification can be executed at once or stored for later use.

During testing, the operator can interrogate the computer at any time to determine the test status. Data acquisition of all critical control parameters is performed by the computer, and the data are available for plotting immediately following the test. Also, data recorded on the 32-track FM tape recorder can be played back, digitized, and processed immediately. A typical plot resulting from on-line data acquisition and reduction is shown in Fig. 8.

The programs described in Table 3 encompass the bulk of testing done at the shaker facility. However, the real advantage of a computerized system becomes evident when unusual requirements are first encountered, as in the case of high-shear-rate tension/compression tests. For these applications, no special hardware or long development programs are necessary. We need only write a short executive program calling the required functional subroutines. 
Table 3. Standard control and data processing programs

\begin{tabular}{lll} 
Program & \multicolumn{1}{c}{ Description } & \multicolumn{1}{c}{ Applications } \\
\hline SINE $^{\mathrm{a}}$ & $\begin{array}{l}\text { Swept-frequency sinusoidal } \\
\text { testing }\end{array}$ & $\begin{array}{l}\text { Resonance surveys, mechanical impedance studies, proof } \\
\text { testing, fatigue tests }\end{array}$ \\
TRAN $^{\mathrm{a}}$ & $\begin{array}{l}\text { Transient response testing } \\
\text { Random vibration testing }\end{array}$ & $\begin{array}{l}\text { Shock spectrum, fatigue tests, seismic simulations } \\
\text { Transportation or flight environment proof testing }\end{array}$ \\
TEN/COM & Tension/compression testing & High-shear-rate material properties, impact tests \\
GPDAP & $\begin{array}{l}\text { General-purpose data analysis } \\
\text { and plotting }\end{array}$ & Post-test spectral and time-domain data analysis \\
\hline
\end{tabular}

${ }^{a}$ Encompass classical shock and vibration tests.

The resulting program then becomes one of our standard capabilities. This adaptability, combined with our flexibility in actuator positioning and fixturing, accommodates test criteria that would be impossible with conventional systems.

\section{Applications}

High performance and computer-controlled versatility distinguish our test facility from other such complexes. The principal features include:

- Capacity to handle large, rigid loads (in excess of 9 tonnes) over a wide frequency range (dc to $500 \mathrm{~Hz}$ ).
- Real-time data acquisition and display during testing.

- Ability to test hazardous materials safely.

- Easy adaptability to nonclassical shock and vibration tests.

This unique combination suits the shaker facility to a wide variety of projects such as materials testing, aerospace structural response studies, seismic proof testing, and conventional ordnance work.

Recently we contracted with the U.S. Air Force Space and Missile Systems Organization to perform shock and vibration tests on two MX upper-stage rocket motors being developed by Aerojet Solid

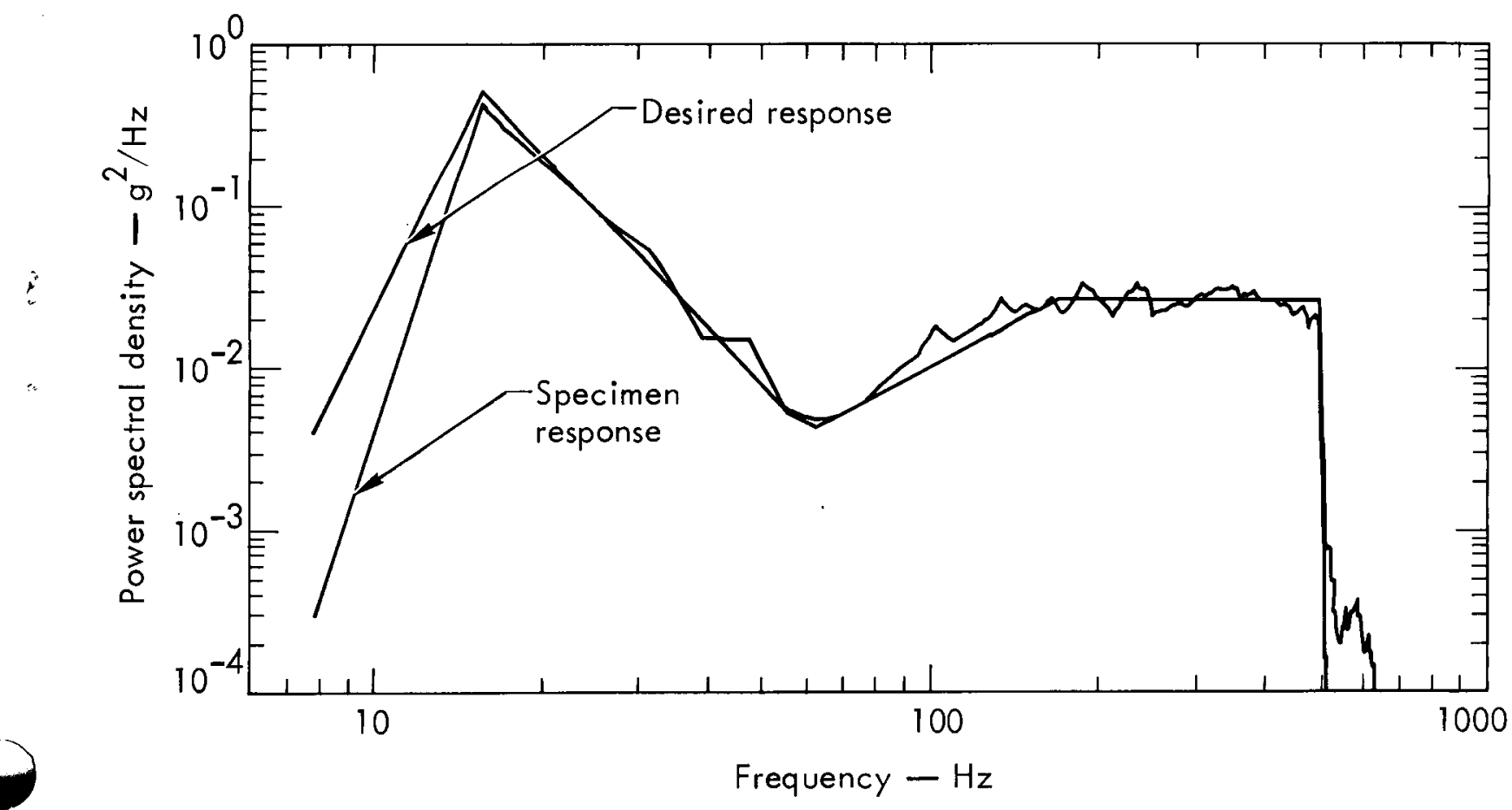

Fig. 8. Results of on-line data acquisition and analysis during random vibration test. 
Propulsion Company; Sacramento, California. To be investigated are the dynamic response characteristics of these motors and their ability to survive specified environments. Our shaker facility is the only test complex equipped to test live rocket motors of this size. Earlier this year, we also did a study for the Army Corps of Engineers to determine the high-stress-rate response characteristics of rock bolts used in mine-tunnel construction. Seismic qualification tests are now under way on an emergency power turbine-generator set to be installed at LLL's plutonium research facility. We are making the test facility available to such users and hope to become involved in other varied projects as its capabilities receive wider recognition.

Key Words: shakers; actuators; dynamic test facility; shock and vibration tests; cross coupling; sinusoidal-response testing; tension/compression tests. 


\section{Notes and References}

1. S. Outcalt, J. Appl. Meteorol. 11, 629 (1972).

2. C. Burchsted and A. Fuller, Design, Construction, and Testing High-Efficiency Air Filtration Systems for Nuclear Applications, Holifield National Laboratory, Oak Ridge, Tenn., Rept. ORNL-NSIC-65 (1970).

3. U.S. Atomic Energy Commission Regulatory Guide 1.60, "Design Response Spectra for Nuclear Power Plants," Rev. 1 (December, 1973).

4. R. Rock and D. Walker, Controlling Employee Exposure to Alpha Radiation in Underground Uranium Mines (U.S. Government Printing Office, Washington, D.C., 1970).

5. The required increase in annual production is from approximately 24000 tonnes (1975) to 53000 tonnes (1985) according to projections by LLL and other agencies.

v 6. H. Hammon, K. Ernst, J. Gaskill, J. Newton, and C. Morris, Development and Evaluation of Radon Sealants for Uranium Mines, Lawrence Livermore Laboratory Rept. UCRL-51818 (1975).

7. M. Salame, Polymer Division Preprints, Amer. Chem. Soc. 8 (1), 137 (1967).

8. D. Fisher, Implementation of a Direct-Digital Multiple-Actuator-Shaker Control System, Lawrence Livermore Laboratory Rept. UCID-16016 (1972).

9. D. Fisher, Shock and Vibration Bull. 43, 153 (1973).

$\mathrm{CSM} / \mathrm{JKP} / \mathrm{md} / \mathrm{lmc}$ 